International Journal of Engineering, Science and Technology

Vol. 1, No. 1, 2009, pp. 272-282
INTERNATIONAL

JOURNAL OF

ENGINEERING,

SCIENCE AND

TECHNOLOGY

www.ijest-ng.com

(C) 2009 MultiCraft Limited. All rights reserved

\title{
Cardinal priority ranking based decision making for economic-emission dispatch problem
}

\author{
Lakhwinder Singh $^{{ }^{*}}$ and J.S. Dhillon ${ }^{2}$ \\ ${ }^{1}$ Department of Electrical Engineering, Baba Banda Singh Bahadur Engineering College, Fatehgarh Sahib -140 407, Punjab, India. \\ ${ }^{2}$ Department of Electrical \& Instrumentation Engineering, Sant Longowal Institute of Engineering \& Technology, \\ Longowal -148 106, Distt. Sangrur, Punjab, India. \\ E-mails:(lakhwinder1968@yahoo.com (Lakhwinder Singh),Corresponding author); jsdhillonp@yahoo.com (J.S. Dhillon)
}

\begin{abstract}
This paper deals with the economic emission dispatch (EED) problem relating to real and reactive power scheduling of thermal power generating units. The formulated EED problem is solved using weighting method to generate non-inferior solutions which allows explicit trade-offs between objective levels for each non-inferior solutions. Fuzzy decision making methodology is exploited to decide the generation schedule. To access the indifference band, interaction with the decision maker is obtained via cardinal priority ranking (CPR) of the objectives. The cardinal priority ranking is constructed in the functional space and then transformed into the decision space, so the cardinal priority ranking of objectives relate the decision maker's preferences to non-inferior solutions through normalized weights. Regression analysis is performed between the cardinal priority ranking and simulated weights to decide the 'best' compromised solution. Decoupled load flow analysis is performed to find the loss coefficients and transmission losses. The validity of the proposed method is demonstrated on IEEE 11-bus system which comprises 3-generators.
\end{abstract}

Keywords: Economic emission dispatch; fuzzy decision making; weighting method, cardinal priority ranking

\section{Introduction}

In a large number of real-life decision problems, a decision maker is faced with difficulties to take a decision, especially when multiple objectives are present in the decision space and these are to be achieved simultaneously. This problem becomes more complicated when the objectives are conflicting, non-commensurable and imprecise in nature. Such types of problems are called multiobjective optimization problems in which the goal is to maximize or minimize several objective functions, simultaneously. For effective operations, the optimal power scheduling problem has mainly confined to minimize the generation cost regardless of emission constraints. With the increase in the environmental awareness and the passage of environmental regulations, the clean air act amendments of 1990 (El-Keib, 1994) has forced utilities to modify their operating strategies to reduce pollution and atmospheric emissions of thermal power generation to meet environmental standards. So the environmental constraints have become of vital concern to system operators to control emissions such as oxides of nitrogen $\left(\mathrm{NO}_{\mathrm{x}}\right)$, oxides of sulphur $\left(\mathrm{SO}_{\mathrm{x}}\right)$ and oxides of carbon $\left(\mathrm{CO}_{\mathrm{x}}\right)$ from thermal plants, which are of greater concern to power utility and communities (Tsay, 2003). The conventional optimization techniques are not suitable to obtain the optimal solution, which simultaneously optimizes a variety of objectives. Multiobjective optimization methodology permits a better simulation of real word problems, often characterized by contrasting/ conflicting goals, and gives the planner the capability of making the final decision by selecting, on the basis of his individual point of view, the most trade-off solution in a wide range of suitable solutions. For the solution of such multiobjective problems different techniques have been reported in literature pertaining to economic-emission dispatch problem (Bath et al., 2004; Chaaban et al., 2004; Singh and Dhillon, 2008). Ramanathan (1994) has presented a methodology to include emission constraints in classical economic dispatch, which contains an efficient weights estimation technique. Talaq et al. (1994) have given a summary of work in the area of environmental/economic dispatch which includes several techniques intended to reduce emissions into the atmosphere due to electric power generation. Hota et al. (2000) have solved the economic emission load 
dispatch through an interactive fuzzy satisfying method. Basu (2002) has used the Hopfield neural networks to solve fuel constrained economic emission load dispatch problem. Chen and Chen (2003) have presented a direct Newton-Raphson economic emission dispatch method which considers the line flow constraints by evaluating the B-coefficients from the sensitivity factors with dc load flow. Abido (2003) has presented a novel approach based on the strength of Pareto evolutionary algorithm to solve environmental/economic power dispatch optimization problem. Fuzzy based mechanism is employed to extract the best compromise solution over the trade-off curve. Brar et al. (2002) have used fuzzy logic based weightage pattern searching to obtain the solution of multiobjective load dispatch problem. The evolutionary optimization technique has been employed in which the 'preferred' weightage pattern is searched to get the 'best' optimal solution in non-inferior domain. An analytical solution technique for combined economic emission dispatch problem has been presented by Palanichamy et al. (2008). The fuel cost as well as the emission characteristics of generating units is represented by their respective equivalent characteristic in terms of power plant total generations.

The intent of the paper is to solve EED problem in which four objectives like operation cost, $\mathrm{NO}_{\mathrm{x}}$ emission, $\mathrm{SO}_{\mathrm{x}}$ emission and $\mathrm{CO}_{\mathrm{x}}$ emission are minimized simultaneously. The objectives are of conflicting nature and improvement in one objective can be reached only by the reduction of other. The formulated EED problem is solved using weighting method to generate non-inferior solutions which allows explicit trade-offs between objective levels for each non-inferior solution. Exploiting fuzzy decision making theory, membership functions relating to objectives are defined those play a vital role to find the 'best alternative' among the non-inferior solutions. To access the indifference band, interaction with the decision maker is obtained via cardinal priority ranking of the objectives. The cardinal priority ranking is constructed in the functional space and then transformed into the decision space, so the cardinal priority ranking of objectives relate the decision maker's preferences to non-inferior solutions through normalized weights. Regression analysis is performed between the cardinal priority ranking and simulated weights to decide the 'best' compromised solution. Decoupled load flow (DLF) analysis is performed to find the loss coefficients, real and reactive power losses. The effectiveness of the proposed method is demonstrated on IEEE 11-bus, 17-lines system, comprising 3generators.

\section{EED problem formulation}

The problem formulation treats EED problem in which the attempt is made to minimize conflicting objective functions simultaneously, while satisfying equality and inequality constraints. Generally the problem is formulated as:

$$
\begin{array}{ll}
\text { Minimize operating cost: } & F_{1}\left(P_{G i}\right)=\sum_{i=1}^{N g}\left(a_{i} P_{G i}^{2}+b_{i} P_{G i}+c_{i}\right) \$ / \mathrm{h} \\
\text { Minimize NOx emission: } & F_{2}\left(P_{G i}\right)=\sum_{i=1}^{N g}\left(d_{2 i} P_{G i}^{2}+e_{2 i} P_{G i}+f_{2 i}\right) \mathrm{kg} / \mathrm{h} \\
\text { Minimize SOx emission: } & F_{3}\left(P_{G i}\right)=\sum_{i=1}^{N g}\left(d_{3 i} P_{G i}^{2}+e_{3 i} P_{G i}+f_{3 i}\right) \mathrm{kg} / \mathrm{h} \\
\text { Minimize CO }{ }_{x} \text { emission: } & F_{4}\left(P_{G i}\right)=\sum_{i=1}^{N g}\left(d_{4 i} P_{G i}^{2}+e_{4 i} P_{G i}+f_{4 i}\right) \mathrm{kg} / \mathrm{h}
\end{array}
$$

where $a_{i}, b_{i}$ and $c_{i}$ are the cost coefficients of $i^{\text {th }}$ generator. $d_{2 i}, e_{2 i}$ and $f_{2 i}$ are the $\mathrm{NO}_{x}$ emission coefficients of $i^{\text {th }}$ generator. $d_{3 i}, e_{3 i}$ and $\mathrm{f}_{3 \mathrm{i}}$ are the $\mathrm{SO}_{\mathrm{x}}$ emission coefficients of $\mathrm{i}^{\text {th }}$ generator. $\mathrm{d}_{4 \mathrm{i}}, \mathrm{e}_{4 \mathrm{i}}$ and $\mathrm{f}_{4 \mathrm{i}}$ are the $\mathrm{CO}_{\mathrm{x}}$ emission coefficients of $\mathrm{i}^{\text {th }}$ generator

\section{Equality constraints}

The total real and reactive powers generated must meet the total demand and losses in the system.

$$
\begin{aligned}
& \sum_{i=1}^{N g} P_{G i}=\sum_{i=1}^{N b} P_{D i}+P_{\text {loss }} \\
& \sum_{i=1}^{N g} Q_{G i}=\sum_{i=1}^{N b} Q_{D i}+Q_{\text {loss }}
\end{aligned}
$$

where $N_{b}$ are the number of buses in the system. $P_{G i}$ and $Q_{G i}$ are the real and reactive powers of $\mathrm{i}^{\text {th }}$ generator, respectively. $P_{D \mathrm{i}}$ and $\mathrm{Q}_{\mathrm{Di}}$ are real and reactive demands at $\mathrm{i}^{\text {th }}$ bus, respectively. $P_{\text {loss }}$ and $Q_{\text {loss }}$ are real and reactive power losses in the transmission lines, respectively. 
Inequality constraints

To ensure stable operation, each generating unit is restricted by its lower and upper limits of real and reactive power outputs.

$$
\begin{gathered}
P_{G i}^{\min } \leq P_{G i} \leq P_{G i}^{\max } \quad ; \mathrm{i}=1,2, \ldots, N g \\
Q_{G i}^{\min } \leq Q_{G i} \leq Q_{G i}^{\max } \quad ; \mathrm{i}=1,2, \ldots, N g
\end{gathered}
$$

where $P_{G i}^{\min }$ and $P_{G i}^{\max }$ are the minimum and maximum values of real power output of i ${ }^{\text {th }}$ unit, respectively. $Q_{G i}^{\min }$ and $Q_{G i}^{\max }$ are the minimum and maximum values of reactive power output of $i^{\text {th }}$ unit, respectively.

\section{Power transmission losses}

The real and reactive power transmission losses, $P_{\text {loss }}$ and $Q_{\text {loss }}$ are given by following equations:

$$
\begin{aligned}
& P_{\text {loss }}=\sum_{i=1}^{N b} \sum_{j=1}^{N b}\left[A_{i j}\left(P_{i} P_{j}+Q_{i} Q_{j}\right)+B_{i j}\left(Q_{i} P_{j}-P_{i} Q_{j}\right)\right] \\
& Q_{\text {loss }}=\sum_{i=1}^{N b} \sum_{j=1}^{N b}\left[C_{i j}\left(P_{i} P_{j}+Q_{i} Q_{j}\right)+D_{i j}\left(Q_{i} P_{j}-P_{i} Q_{j}\right)\right]
\end{aligned}
$$

where

$$
\begin{array}{ll}
P_{i}+j Q_{i}=\left(P_{G i}-P_{D i}\right)+j\left(Q_{G i}-Q_{D i}\right) & \\
A_{i j}=\frac{R_{i j}}{\left|V_{i}\right|\left|V_{j}\right|} \cos \left(\delta_{i}-\delta_{j}\right) ; & B_{i j}=\frac{R_{i j}}{\left|V_{i}\right|\left|V_{j}\right|} \sin \left(\delta_{i}-\delta_{j}\right) \\
C_{i j}=\frac{X_{i j}}{\left|V_{i}\right|\left|V_{j}\right|} \cos \left(\delta_{i}-\delta_{j}\right) ; & D_{i j}=\frac{X_{i j}}{\left|V_{i}\right|\left|V_{j}\right|} \sin \left(\delta_{i}-\delta_{j}\right)
\end{array}
$$

with $A_{i j}, B_{i j}, C_{i j}$ and $D_{i j}$ are loss coefficients, and are evaluated from line data by performing DLF analysis. $\delta_{i}$ and $\delta_{j}$ are load angles at $i^{\text {th }}$ and $j^{\text {th }}$ buses, respectively. $V_{i}$ and $V_{j}$ are voltage magnitude at $i^{\text {th }}$ and $j^{\text {th }}$ buses, respectively. $R_{i j}$ is the real component of impedance bus matrix. $X_{i j}$ is the reactive component of impedance bus matrix (Dhillon, 1993).

\section{Solution procedure}

To generate the non-inferior solutions, the multiobjective problem is converted into scalar optimization problem as:

$$
\text { Minimize } \sum_{j=1}^{L} w_{j} F_{j}
$$

Subject to:

$$
\text { i) } \sum_{j=1}^{L} w_{j}=1.0, \quad w_{j} \geq 0.0
$$

ii) Eq. (5) to (8)

where $\mathrm{w}_{\mathrm{j}}$ are the levels of the weighting coefficients. $\mathrm{L}$ is the total number of objectives. The sum of all weights is equal to one. To find the solution, constrained problem is converted into an unconstrained problem. Equality and inequality constraints are clubbed with objective function to form generalized augmented function as: 


$$
\begin{aligned}
& L\left(P_{G i}, Q_{G i}, \lambda_{p}, \lambda_{q}\right)=\sum_{j=1}^{L} w_{j} F_{j}-\lambda_{p}\left(\sum_{i=1}^{N g} P_{G i}-\sum_{i=1}^{N b} P_{D i}-P_{\text {loss }}\right)-\lambda_{q}\left(\sum_{i=1}^{N g} Q_{G i}-\sum_{i=1}^{N b} Q_{D i}-Q_{\text {loss }}\right) \\
& +\left\langle U_{P G i}\right\rangle+\left\langle U_{Q G i}\right\rangle \\
& \int \frac{1}{r_{1}^{k}}\left[\sum_{i=1}^{N g}\left(P_{G i}-P_{G i}^{\min }\right)^{2}\right] \quad ; P_{G i}<P_{G i}^{\min } \\
& \left\langle U_{P G i}\right\rangle= \begin{cases}0 & ; P_{G i}^{\min } \leq P_{G i} \leq P_{G i}^{\max } \\
\frac{1}{r_{1}^{k}}\left[\sum_{i=1}^{N g}\left(P_{G i}-P_{G i}^{\max }\right)^{2}\right] & ; P_{G i}>P_{G i}^{\max }\end{cases} \\
& \left\langle U_{Q G i}\right\rangle= \begin{cases}\frac{1}{r_{1}^{k}}\left[\sum_{i=1}^{N g}\left(Q_{G i}-Q_{G i}^{\min }\right)^{2}\right] & ; Q_{G i}<Q_{G i}^{\min } \\
0 & ; Q_{G i}^{\min } \leq Q_{G i} \leq Q_{G i}^{\max } \\
\frac{1}{r_{1}^{k}}\left[\sum_{i=1}^{N g}\left(Q_{G i}-Q_{G i}^{\max }\right)^{2}\right] & ; Q_{G i}>Q_{G i}^{\max }\end{cases}
\end{aligned}
$$

where

$\lambda_{p}, \lambda_{q}$ are lagrangian multipliers, $r_{1}^{k}$ is penalty factor. The Newton-Raphson method is applied to obtain the non-inferior solutions for simulated weight combinations, to achieve the necessary conditions.

\section{Cardinal priority ranking}

The fuzzy sets are defined by equations called membership functions, which represent the goals of each objective function. The membership function represents the degree of achievement of the original objective function as a value between 0 and 1 with $\mu\left(F_{i}\right)=1$ as completely satisfactory and $\mu\left(F_{i}\right)=0$ as unsatisfactory. Such a linear membership function represents the decision maker's fuzzy goal of achievement, and at the same time scales the original objective functions with different physical units into measure of 0-1. By taking account of the minimum and maximum values of each objective function together with the rate of increase of membership satisfaction, the decision maker must determine the membership function $\mu\left(F_{i}\right)$ in a subjective manner.

$$
\mu\left(F_{i}\right)= \begin{cases}1 & ; F_{i} \leq F_{i}^{\min } \\ \frac{F_{i}^{\max }-F_{i}}{F_{i}^{\max }-F_{i}^{\min }} & ; F_{i}^{\min } \leq F_{i} \leq F_{i}^{\max } \\ 0 & ; F_{i} \geq F_{i}^{\max }\end{cases}
$$

where $F_{i}^{\text {min }}$ and $F_{i}{ }^{\text {max }}$ are minimum and maximum values of $\mathrm{i}^{\text {th }}$ objective function in which the solution is expected. The value of the membership function indicates how much (in the scale from 0 to 1 ) a non-inferior solution has satisfied the $F_{i}$ objective. The sum of the membership function values $\left(\mu\left(F_{i}\right) ; \mathrm{i}=1,2, \ldots, \mathrm{L}\right)$ for all the objectives can be computed in order to measure the 'accomplishment' of each solution in satisfying the objectives. The 'accomplishment' of each non-dominated solution can be rated with respect to all the $\mathrm{M}$ non-dominated solutions by normalizing its 'accomplishment' over the sum of the 'accomplishment' of the $\mathrm{M}$ non-dominated solutions as follows:

$$
\mu_{D}^{k}=\frac{\sum_{i=1}^{L} \bar{\mu}\left(F_{i}\right)^{k}}{\sum_{k=1}^{M} \sum_{i=1}^{L} \bar{\mu}\left(F_{i}\right)^{k}}
$$


where

$$
\bar{\mu}\left(F_{i}\right)^{k}=1-\mu\left(F_{i}\right)^{k}
$$

The function $\mu_{D}^{k}$ can be treated as an unsatisfied membership function for non-dominated solutions in a fuzzy set and represented as a fuzzy cardinal priority ranking of the non-dominated solutions. The smaller the unsatisfied cardinal priority, the better is the solution. The function $S^{k}$ is defined as:

$$
S^{k}=\left\{S^{\min }+\mu_{D}^{k}\left(S^{\max }-S^{\min }\right)\right\}
$$

where $S^{\min }$ and $S^{\max }$ are minimum and maximum values of scaling factor to map the function, $S^{k}$ in the required range to adjust the cardinal priority. Regression analysis is performed between cardinal priority ranking and simulated weights, $w_{i} ; \mathrm{i}=1,2, \ldots$, L to achieve maximum satisfaction.

\section{Flow chart}

The economic emission dispatch problem is solved by various steps. The step wise procedure is depicted in flow chart given in Figure 1.

\section{Test system and results}

The validity of the proposed method is illustrated on 11-bus, 17-lines IEEE system, comprising of three generators (Singh et al., 2006). Minimum and maximum values of the objectives are obtained by performing minimum economic and emission dispatch respectively. Minimum and maximum values of the objectives are shown in Table 1.

Table 1: Minimum and maximum values of objectives

\begin{tabular}{|l|l|}
\hline$F_{1}^{\min }=4584.7830 \$ / \mathrm{h}$ & $F_{1}^{\max }=4742.0610 \$ / \mathrm{h}$ \\
\hline$F_{2}^{\min }=619.1288 \mathrm{~kg} / \mathrm{h}$ & $F_{2}^{\max }=953.5742 \mathrm{~kg} / \mathrm{h}$ \\
\hline$F_{3}^{\min }=2848.7130 \mathrm{~kg} / \mathrm{h}$ & $F_{3}^{\max }=6246.4340 \mathrm{~kg} / \mathrm{h}$ \\
\hline$F_{4}^{\min }=5.887253 \mathrm{~kg} / \mathrm{h}$ & $F_{4}^{\max }=15.05706 \mathrm{~kg} / \mathrm{h}$ \\
\hline
\end{tabular}

To obtain the solution of EED problem, three different cases are considered in which weights are simulated with different step sizes so that their sum remains equal to one and are as:

Case-I: Weights are simulated by giving variation in step of 0.05

Case-II: Weights are simulated by giving variation in step of 0.02

Case-III: Weights are simulated by giving variation in step of 0.01

Non-inferior solutions, corresponding membership functions for all the objectives along with the cardinal priority ranking for the simulated weight combinations are shown in Table 2, Table 3 and Table 4 for all the above three cases. 


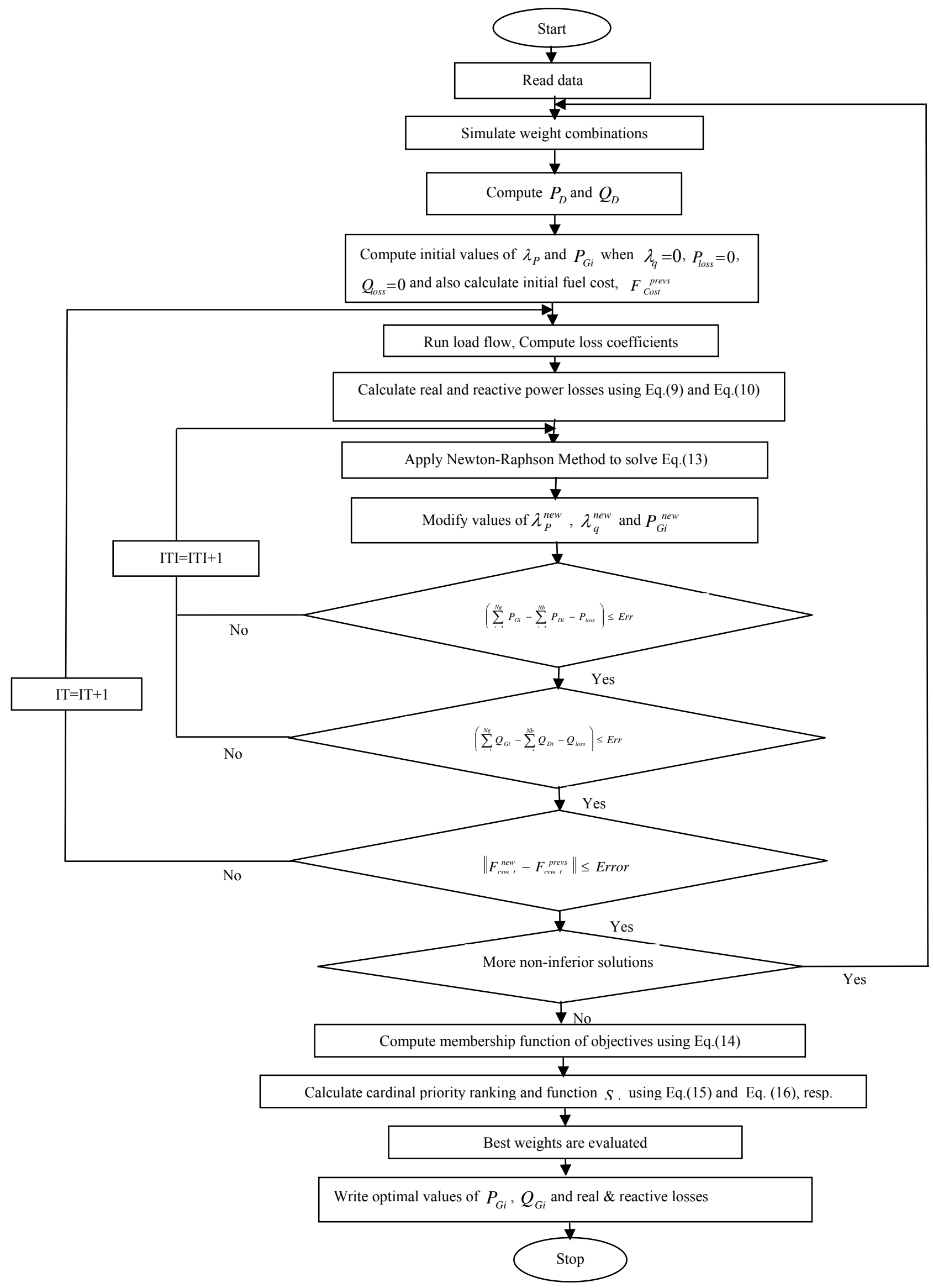

Figure 1: Flow chart for economic emission dispatch problem 
Table 2: Non-inferior solutions, membership functions and cardinal priority ranking for case-I

\begin{tabular}{|c|c|c|c|c|c|c|c|c|c|}
\hline \multicolumn{4}{|c|}{ Weights } & \multicolumn{6}{|c|}{ Objectives and membership functions } \\
\hline \multirow[b]{2}{*}{$w_{1}$} & \multirow[b]{2}{*}{$w_{2}$} & \multirow[b]{2}{*}{$w_{3}$} & \multirow[b]{2}{*}{$w_{4}$} & Objectives & $F_{1} \$ / \mathrm{h}$ & $F_{2} \mathrm{~kg} / \mathrm{h}$ & $F_{3} \mathrm{~kg} / \mathrm{h}$ & $F_{4} \mathrm{~kg} / \mathrm{h}$ & \multirow[t]{2}{*}{$S^{k}$} \\
\hline & & & & Membership & $\mu\left(F_{1}\right)$ & $\mu\left(F_{2}\right)$ & $\mu\left(F_{3}\right)$ & $\mu\left(F_{4}\right)$ & \\
\hline \multirow{2}{*}{0.25} & \multirow{2}{*}{0.25} & \multirow{2}{*}{0.25} & \multirow{2}{*}{0.25} & Objectives & 4701.1930 & 863.6878 & 2899.6690 & 9.214497 & \multirow{2}{*}{0.7900239} \\
\hline & & & & Membership & 0.740153 & 0.731237 & 0.014997 & 0.362848 & \\
\hline \multirow{2}{*}{0.20} & \multirow{2}{*}{0.20} & \multirow{2}{*}{0.30} & \multirow{2}{*}{0.30} & Objectives & 4713.5030 & 885.0974 & 2874.9760 & 9.344164 & \multirow[b]{2}{*}{0.8537466} \\
\hline & & & & Membership & 0.818423 & 0.795253 & 0.007730 & 0.376988 & \\
\hline \multirow{2}{*}{0.30} & \multirow{2}{*}{0.30} & \multirow{2}{*}{0.20} & \multirow{2}{*}{0.20} & Objectives & 4685.3470 & 837.9921 & 2945.2890 & 9.039403 & \multirow{2}{*}{0.7117372} \\
\hline & & & & Membership & 0.639403 & 0.654407 & 0.028424 & 0.343753 & \\
\hline \multirow{2}{*}{0.20} & \multirow{2}{*}{0.30} & \multirow{2}{*}{0.30} & \multirow{2}{*}{0.20} & Objectives & 4711.3310 & 866.9720 & 2892.6060 & 9.467503 & \multirow[b]{2}{*}{0.8326569} \\
\hline & & & & Membership & 0.804613 & 0.741057 & 0.012918 & 0.390439 & \\
\hline \multirow{2}{*}{0.30} & \multirow{2}{*}{0.20} & \multirow{2}{*}{0.20} & \multirow{2}{*}{0.30} & Objectives & 4689.8210 & 858.0472 & 2913.2680 & 8.939130 & \\
\hline & & & & Membership & 0.667847 & 0.714372 & 0.019000 & 0.332818 & 0.7408092 \\
\hline 015 & 015 & 035 & 035 & Objectives & 4723.0240 & 903.7136 & 2861.3140 & 9.432228 & \\
\hline & & & & Membership & 0.878959 & 0.850916 & 0.003709 & 0.386592 & 0.9057738 \\
\hline 025 & 025 & 015 & 015 & Objectives & 4706.1980 & 752.3051 & 3217.0410 & 10.69450 & \\
\hline & & & & Membership & 0.771978 & 0.398200 & 0.108404 & 0.524247 & 0.7 \\
\hline 015 & 035 & 035 & 015 & Objectives & 4720.8640 & 868.8564 & 2889.2360 & 9.709036 & \\
\hline & & & & Membership & 0.865224 & 0.746692 & 0.011927 & 0.416779 & 0.8717871 \\
\hline 035 & 015 & 015 & 035 & Objectives & 4676.0400 & 848.1931 & 2940.1950 & 8.621339 & \\
\hline & & & & Membership & 0.580227 & 0.684908 & 0.026925 & 0.298162 & 0.6793687 \\
\hline 010 & 0 & 040 & 040 & Objectives & 4730.3710 & 920.6932 & 2853.7960 & 9.483382 & \\
\hline 0.10 & 0.10 & 0.40 & 0.40 & Membership & 0.925673 & 0.901685 & 0.001496 & 0.392171 & 0.9488586 \\
\hline 010 & $0+10$ & 040 & 010 & Objectives & 4730.1370 & 869.8763 & 2888.1770 & 9.945444 & \\
\hline & & & & Membership & 0.924186 & 0.749741 & 0.011615 & 0.442560 & 0.9091604 \\
\hline 005 & 005 & 045 & 045 & Objectives & 4736.1320 & 937.0949 & 2849.9040 & 9.502926 & \\
\hline & & & & Membership & 0.962301 & 0.950726 & 0.000351 & 0.394302 & 0.9858791 \\
\hline
\end{tabular}

By performing linear regression analysis, the obtained best values of weights and the corresponding values of fuel cost, $\mathrm{NO}_{\mathrm{x}}$ emission, $\mathrm{SO}_{\mathrm{x}}$ emission, $\mathrm{CO}_{\mathrm{x}}$ emission for all the three cases are compared and are shown in Table 5. It has been observed from Case-I, Case-II and Case-III that the minimum value of the membership functions of the objectives is improved by decreasing the step size of the weights. The membership function increases from 0.5165955 to 0.5241862 with the decrease in step size from 0.05 to 0.02 and further 0.5241862 to 0.5430062 with the decrease in step size from 0.02 to 0.01 . The results obtained in the proposed method are also compared with the results of Brar et al. (2002). It has been observed that, the solutions achieved in proposed method have more membership satisfaction as compared to the results presented in Brar et al. (2002). It is clear from all the three cases that by reducing the step size of the weights, better membership satisfaction is achieved and when the overall outcome is less than some of the non-inferior solutions try with the reduced step size which will improve the overall outcome. The 'best' power generation schedule for all the three cases of proposed method is given in Table 6. 
Table 3: Non-inferior solutions, membership functions and cardinal priority ranking for case-II

\begin{tabular}{|c|c|c|c|c|c|c|c|c|c|}
\hline \multicolumn{4}{|c|}{ Weights } & \multicolumn{6}{|c|}{ Objectives and membership functions } \\
\hline \multirow[b]{2}{*}{$w_{1}$} & \multirow[b]{2}{*}{$w_{2}$} & \multirow[b]{2}{*}{$w_{3}$} & \multirow[b]{2}{*}{$w_{4}$} & Objectives & $F_{1} \$ / \mathrm{h}$ & $F_{2} \mathrm{~kg} / \mathrm{h}$ & $F_{3} \mathrm{~kg} / \mathrm{h}$ & $F_{4} \mathrm{~kg} / \mathrm{h}$ & \multirow[t]{2}{*}{$S^{k}$} \\
\hline & & & & Membership & $\mu\left(F_{1}\right)$ & $\mu\left(F_{2}\right)$ & $\mu\left(F_{3}\right)$ & $\mu\left(F_{4}\right)$ & \\
\hline \multirow[t]{2}{*}{0.24} & \multirow[t]{2}{*}{0.24} & \multirow[t]{2}{*}{0.26} & \multirow[t]{2}{*}{0.26} & Objectives & 4703.9120 & 868.2581 & 2893.4810 & 9.243966 & \multirow{2}{*}{0.08304875} \\
\hline & & & & Membership & 0.757442 & 0.744903 & 0.013176 & 0.366062 & \\
\hline \multirow[t]{2}{*}{0.26} & \multirow[t]{2}{*}{0.26} & \multirow[t]{2}{*}{0.24} & \multirow[t]{2}{*}{0.24} & Objectives & 4698.3330 & 858.9479 & 2906.6590 & 9.183201 & \multirow{2}{*}{0.08013305} \\
\hline & & & & Membership & 0.721970 & 0.717065 & 0.017054 & 0.359435 & \\
\hline \multirow{2}{*}{0.24} & \multirow[t]{2}{*}{0.26} & \multirow[t]{2}{*}{0.26} & \multirow{2}{*}{0.24} & Objectives & 4703.2930 & 864.4938 & 2897.8570 & 9.266447 & \multirow{2}{*}{0.08254325} \\
\hline & & & & Membership & 0.753506 & 0.733647 & 0.014464 & 0.368513 & \\
\hline \multirow[t]{2}{*}{0.26} & \multirow[t]{2}{*}{0.24} & \multirow[t]{2}{*}{0.24} & \multirow[t]{2}{*}{0.26} & Objectives & 4699.0450 & 862.7900 & 2901.7310 & 9.161678 & \multirow{2}{*}{0.08067229} \\
\hline & & & & Membership & 0.726496 & 0.728553 & 0.015604 & 0.357088 & \\
\hline \multirow[t]{2}{*}{0.22} & \multirow[t]{2}{*}{0.22} & \multirow[t]{2}{*}{0.28} & \multirow[t]{2}{*}{0.28} & Objectives & 4708.9530 & 876.9422 & 2883.1320 & 9.297540 & \\
\hline & & & & Membership & 0.789494 & 0.770868 & 0.010130 & 0.371904 & 0.08573294 \\
\hline 0.22 & 0.28 & 0.28 & 0.22 & Objectives & 4707.3750 & 865.8672 & 2894.8760 & 9.368151 & \\
\hline & & & & Membership & 0.779460 & 0.737754 & 0.013586 & 0.379604 & 2090 \\
\hline 0.28 & 0.28 & 0.22 & 0.22 & Objectives & 4692.1590 & 848.9004 & 2923.5310 & 9.115059 & \\
\hline & & & & Membership & 0.682715 & 0.687023 & 0.022020 & 0.352004 & 0.07696564 \\
\hline 0.20 & 0.20 & 0.30 & 0.30 & Objectives & 4713.5030 & 885.0973 & 2874.9760 & 9.344166 & \\
\hline & & & & Membership & 0.818423 & 0.795252 & 0.007730 & 0.376989 & 0.08820449 \\
\hline 0.20 & 0.30 & 0.30 & 0.20 & Objectives & 4711.3300 & 866.9719 & 2892.6060 & 9.467499 & \\
\hline & & & & Membership & 0.804607 & 0.741057 & 0.012918 & 0.390438 & 0.08602533 \\
\hline 0.18 & 0.18 & 0.32 & 0.32 & Objectives & 4717.6100 & 892.8093 & 2868.5340 & 9.384130 & \\
\hline & & & & Membership & 0.844535 & 0.818312 & 0.005834 & 0.381347 & 0.09048350 \\
\hline 0.32 & 0.18 & 0.18 & 0.32 & Objectives & 4684.6950 & 854.7670 & 2921.8040 & 8.818712 & \\
\hline & & & & Membership & 0.635256 & 0.704564 & 0.021512 & 0.319686 & 0.07419626 \\
\hline 0.18 & 0.32 & 0.32 & 0.18 & Objectives & 4715.1920 & 867.8572 & 2890.9120 & 9.565063 & \\
\hline & & & & Membership & 0.829161 & 0.743704 & 0.012420 & 0.401078 & 0.08767353 \\
\hline
\end{tabular}


Table 4: Non-inferior solutions, membership functions and cardinal priority ranking for case-III

\begin{tabular}{|c|c|c|c|c|c|c|c|c|c|}
\hline \multicolumn{4}{|c|}{ Weights } & \multicolumn{6}{|c|}{ Objectives and membership functions } \\
\hline \multirow[b]{2}{*}{$w_{1}$} & \multirow[b]{2}{*}{$w_{2}$} & \multirow[b]{2}{*}{$w_{3}$} & \multirow[b]{2}{*}{$w_{4}$} & Objectives & $F_{1} \$ / \mathrm{h}$ & $F_{2} \mathrm{~kg} / \mathrm{h}$ & $F_{3} \mathrm{~kg} / \mathrm{h}$ & $F_{4} \mathrm{~kg} / \mathrm{h}$ & \multirow[t]{2}{*}{$S^{k}$} \\
\hline & & & & Membership & $\mu\left(F_{1}\right)$ & $\mu\left(F_{2}\right)$ & $\mu\left(F_{3}\right)$ & $\mu\left(F_{4}\right)$ & \\
\hline \multirow[t]{2}{*}{0.25} & \multirow[t]{2}{*}{0.25} & \multirow[t]{2}{*}{0.25} & \multirow[t]{2}{*}{0.25} & Objectives & 4701.1930 & 863.6878 & 2899.6690 & 9.214497 & \multirow{2}{*}{0.08131214} \\
\hline & & & & Membership & 0.740153 & 0.731237 & 0.014997 & 0.362848 & \\
\hline \multirow[t]{2}{*}{0.26} & \multirow[t]{2}{*}{0.26} & \multirow[t]{2}{*}{0.24} & \multirow[t]{2}{*}{0.24} & Objectives & 4698.3330 & 858.9479 & 2906.6590 & 9.183201 & \multirow{2}{*}{0.07982981} \\
\hline & & & & Membership & 0.721970 & 0.717065 & 0.017054 & 0.359435 & \\
\hline \multirow{2}{*}{0.24} & \multirow{2}{*}{0.26} & \multirow[t]{2}{*}{0.26} & \multirow[t]{2}{*}{0.24} & Objectives & 4703.2930 & 864.4938 & 2897.8570 & 9.266446 & \multirow[b]{2}{*}{0.08223089} \\
\hline & & & & Membership & 0.753506 & 0.733647 & 0.014464 & 0.368513 & \\
\hline \multirow[t]{2}{*}{0.23} & \multirow[t]{2}{*}{0.23} & \multirow[t]{2}{*}{0.27} & \multirow[t]{2}{*}{0.27} & Objectives & 4706.4970 & 872.6721 & 2887.9970 & 9.271636 & \multirow[b]{2}{*}{0.08409920} \\
\hline & & & & Membership & 0.773878 & 0.758101 & 0.011562 & 0.369079 & \\
\hline \multirow[t]{2}{*}{0.23} & \multirow[t]{2}{*}{0.27} & \multirow[t]{2}{*}{0.27} & \multirow[t]{2}{*}{0.23} & Objectives & 4705.3530 & 865.2177 & 2896.2670 & 9.317632 & \\
\hline & & & & Membership & 0.766604 & 0.735812 & 0.013996 & 0.374095 & 0.08312687 \\
\hline 0.27 & 0.27 & 0.23 & 0.23 & Objectives & 4695.3240 & 854.0240 & 2914.5690 & 9.150059 & \\
\hline & & & & Membership & 0.702839 & 0.702342 & 0.019382 & 0.355821 & 473 \\
\hline 0.22 & 0.22 & 0.28 & 0.28 & Objectives & 4708.9530 & 876.9423 & 2883.1330 & 9.297540 & \\
\hline & & & & Membership & 0.789494 & 0.770869 & 0.010130 & 0.371904 & 0.08540853 \\
\hline 0.28 & 0.28 & 0.22 & 0.22 & Objectives & 4692.1590 & 848.9002 & 2923.5310 & 9.115069 & \\
\hline & & & & Membership & 0.682715 & 0.687022 & 0.022020 & 0.352005 & 0.07667442 \\
\hline 0.21 & 0.21 & 0.29 & 0.29 & Objectives & 4711.2870 & 881.0804 & 2878.8130 & 9.321701 & \\
\hline & & & & Membership & 0.804334 & 0.783242 & 0.008859 & 0.374539 & 0.08666504 \\
\hline 0.20 & 0.30 & 0.30 & 0.20 & Objectives & 4711.3310 & 866.9720 & 2892.6060 & 9.467502 & \\
\hline & & & & Membership & 0.804613 & 0.741057 & 0.012918 & 0.390439 & 0.08570008 \\
\hline 0.19 & 0.31 & 0.31 & 0.19 & Objectives & 4713.2720 & 867.4395 & 2891.6940 & 9.516477 & \\
\hline & & & & Membership & 0.816954 & 0.742455 & 0.012650 & 0.395780 & 0.08652723 \\
\hline 0.18 & 0.18 & 0.32 & 0.32 & Objectives & 4717.6100 & 892.8094 & 2868.5340 & 9.384129 & \\
\hline & & & & Membership & 0.844535 & 0.818312 & 0.005834 & 0.381347 & 0.09014110 \\
\hline
\end{tabular}

Table 5: Comparison of results

\begin{tabular}{|c|c|c|c|c|c|}
\hline \multirow{4}{*}{ Case-I } & $\begin{array}{c}\text { Cost } \\
(\$ \mathrm{~h} h)\end{array}$ & $\begin{array}{c}\mathrm{NO}_{\mathrm{x}} \text { emission } \\
(\mathrm{kg} / \mathrm{h})\end{array}$ & $\begin{array}{c}\mathrm{SO}_{\mathrm{x}} \text { emission } \\
(\mathrm{kg} / \mathrm{h})\end{array}$ & $\begin{array}{c}\mathrm{CO}_{\mathrm{x}} \text { emission } \\
(\mathrm{kg} / \mathrm{h})\end{array}$ \\
\cline { 2 - 6 } & Weights & 0.1355 & 0.4247 & 0.0753 & 0.3645 \\
\cline { 2 - 6 } & Objectives & 4660.8120 & 744.4364 & 3278.2300 & 9.624076 \\
\cline { 2 - 6 } Case-II & Membership & 0.5165955 & 0.6253272 & 0.8735867 & 0.5924862 \\
\cline { 2 - 6 } & Weights & 0.1737 & 0.3660 & 0.0854 & 0.3748 \\
\cline { 2 - 6 } & Objectives & 4659.6180 & 765.2352 & 3177.3690 & 9.243322 \\
\cline { 2 - 6 } & Membership & 0.5241862 & 0.5631382 & 0.9032716 & 0.6340087 \\
\hline \multirow{3}{*}{ Case-III } & Weights & 0.1872 & 0.4139 & 0.0861 & 0.3128 \\
\cline { 2 - 6 } & Objectives & 4656.6580 & 756.0088 & 3223.5530 & 9.296052 \\
\cline { 2 - 6 } $\begin{array}{c}\text { Brar } \text { et al. } \\
\text { (2002) }\end{array}$ & Membership & 0.5430062 & 0.5907254 & 0.8896790 & 0.6282583 \\
\cline { 2 - 6 } & Weights & 0.5400 & 0.2070 & 0.1270 & 0.1260 \\
\cline { 2 - 6 } & Mejectives & 4650.108 & 810.5679 & 3052.2760 & 8.243926 \\
\hline
\end{tabular}


Table 6: Generation schedule corresponding to optimal solutions

\begin{tabular}{|c|l|l|l|c|}
\hline Optimal values & Case-I & Case-II & Case-III & Brar et al. (2002) \\
\hline$P_{G 1}$ (p.u.) & 2.4461 & 2.4235 & 2.4155 & 2.2664 \\
\hline$P_{G 2}$ (p.u.) & 0.6624 & 0.5897 & 0.6256 & 0.4888 \\
\hline$P_{G 3}$ (p.u.) & 1.1012 & 1.1973 & 1.1654 & 1.4428 \\
\hline$Q_{G 1}$ (p.u.) & 0.7217 & 0.7200 & 0.7171 & 0.6988 \\
\hline$Q_{G 2}$ (p.u.) & 0.7248 & 0.7351 & 0.7250 & 0.7390 \\
\hline$Q_{G 3}$ (p.u.) & 0.3942 & 0.3946 & 0.3916 & 0.3808 \\
\hline$P_{\text {loss }}$ & 0.3635 & 0.3647 & 0.3605 & 0.3618 \\
\hline$Q_{\text {loss }}$ & 0.5777 & 0.5872 & 0.5710 & 0.5762 \\
\hline
\end{tabular}

\section{Conclusions}

The solution set of the problem is non-inferior due to conflicting nature of the objectives and has been obtained through weighting method. The novel formulation as economic emission dispatch problem has made it possible to quantitatively grasp trade-off relations among conflicting objectives. The trade-off approach is effective only for two objectives, as the number of objectives increases the selection of best solution becomes cumbersome. Exploiting fuzzy set theory an interactive cardinal priority ranking method has been applied to identify the best compromise solution for EED problem, when conflicting objectives are more than two. The major characteristics and advantages of the cardinal priority ranking method are that the cardinal priority ranking functions, which relate the decision maker's preference to the non-inferior, solutions though the trade-off functions, are constructed in the functional space and only then are transformed in to the decision space. The proposed method provides interface between the decision maker and the mathematical model through cardinal priority ranking. It also allows explicit tradeoff between fuel cost of units with $\mathrm{NO}_{\mathrm{x}}$ emission, $\mathrm{SO}_{\mathrm{x}}$ emission and $\mathrm{CO}_{\mathrm{x}}$ emission levels, respectively. Results of the proposed method are compared with Brar et al. (2002). The proposed method gives better results in terms of overall membership satisfaction and real and reactive power losses. Study can be extended by adopting $\varepsilon$-constraint method or shifted min-max method to generate the non-inferior solution surface. Generally, the weights are either simulated or searched in the non-inferior domain. Evolutionary search technique may be implemented to search the 'preferred' weightage pattern in the non-inferior domain, which may correspond to the 'best' compromised solution.

\section{References}

Abido M.A., 2003. Environmental/economic power dispatch using multiobjective evolutionary algorithms, IEEE Trans on Power Systems, Vol. 18, No. 4, pp. 1529-1537.

Basu M., 2002. Fuel constrained economic emission load dispatch using Hopfield neural networks, Electric Power Systems Research, Vol. 63, pp. 51-57.

Bath S.K, Dhillon J.S. and Kothari D.P., 2004. Fuzzy satisfying stochastic multi-objective generation scheduling by weightage pattern search methods, Electric Power Systems Research, Vol. 69, pp. 311-320.

Brar Y.S., Dhillon J.S., and Kothari D.P., 2002. Multi-objective load dispatch by fuzzy logic searching weightage pattern, Electric Power Systems Research, Vol. 63, pp. 149-160.

Chaaban F.B., Mezher T. and Ouwayjan M., 2004. Options for emissions reduction from power plants: an economic evaluation, International Journal of Electrical Power \& Energy Systems, Vol. 26, No. 1, pp. 57-63.

Chen S.D., and Chen J.F., 2003. A direct Newton-Raphson economic emission dispatch, International Journal of Electrical Power \& Energy Systems, Vol. 25, pp. 411-417.

El-Keib A.A., Ma H. and Hart J.L., 1994. Economic dispatch in view of clean air Act of 1990, IEEE Trans on Power Systems, Vol. 9, No. 3, pp. 972-978.

Hota P.K., Chakrabarti R., and Chattopadhyay D.P.K., 2000. Economic emission load dispatch through an interactive fuzzy satisfying method, Electric Power Systems Research, Vol. 54, pp.151-157.

Palanichamy C. and Babu N.S., 2008. Analytical solution for combined economic and emissions dispatch, Electric Power Systems Research, Vol. 78, No. 7, pp. 1129-1137.

Ramanathan R., 1994. Emission constrained economic dispatch, IEEE Trans on Power Systems, Vol. 9, No. 4, pp. 1994-2000. 
Talaq J.H., El-Hawary F., and El-Hawary M.E., 1994. A summary of environmental/ economic dispatch algorithms, IEEE Trans on Power Systems, Vol. 9, No. 3, pp.1508-1516.

Singh L., Dhillon J.S., and Chauhan R.C., 2006. Evaluation of best weight pattern for multiple criteria load dispatch, Electric Power Components and Systems, Vol. 34, No.1, pp. 21-35.

Singh L. and Dhillon J.S., 2008. Secure multiobjective real and reactive power allocation of thermal power units, International Journal of Electrical Power \& Energy Systems, Vol. 30, No. 10, pp. 594-602.

Tsay M.T., 2003. Applying the multi-objective approach for operation strategy of cogeneration systems under environment constraints, International Journal of Electrical Power \& Energy Systems, Vol. 25, pp. 219-226.

\section{Biographical notes}

Lakhwinder Singh is Associate Professor \& Head, Department of Electrical Engineering, Baba Banda Singh Bahadur Engineering College, Fatehgarh Sahib. He obtained his B.E. (Electrical) (1990) from Guru Nanak Dev Engineering College, Ludhiana and M.E. (Power Systems) (1995) from Punjab University, Chandigarh. He is currently pursuing Ph.D. from Punjab Technical University, Jallandhar. He is a life member of the Indian Society for Technical Education, and a member of the Institution of Engineers (India). He has published/presented 29 papers in national and international conferences/ journals. His research interests include power system operation, optimization, neural networks and fuzzy logic.

J.S.Dhillon is Professor, Electrical and Instrumentation Engineering Department, Sant Longowal Institute of Engineering and Technology, Longowal, India (Deemed University). He received his B.E. (Electrical) (1983) from Guru Nanak Dev Engineering College, Ludhiana, M.E. (Systems) (1987), Punjab Agricultural University, Ludhiana, Ph.D., (1996) Thapar Institute of Engineering \& Technology, Patiala. His research activities include Microprocessor applications, Multi-objective thermal dispatch, hydrothermal scheduling, Optimization, Neural Networks, Fuzzy theory and soft computing applications in Power system. A member of 'The Institution of Engineers (India)', Life Member: ISTE, Life Member: SSI, has supervised 02 Ph.D, 13 M.E. scholars and supervising 06 Ph.D. Scholars. He has contributed in these areas as evidenced by 87 research papers published in various national and international Journals/ proceedings. He has co-authored 02 books "Power System Optimization", PHI, Publication, "Principles of Electrical \& Electronics Engineering, Kalyani Publication.

Received December 2009

Accepted December 2009

Final acceptance in revised form December 2009 